\title{
Creating State or Regional Dental Registries to Identify Pediatric Dental Abuse or Neglect
}

\author{
*David R Katner JD \\ Tulane University Law School, USA
}

Received: October 13, 2017; Published: October 20, 2017

*Corresponding author: David R Katner JD, Tulane University Law School, Tulane Law School 6329 Freret St. New Orleans, LA 70118, USA,

\section{Public Policy}

In 1967, the American Dental Association published an editorial noting dentists' infrequent reporting of cases involving child abuse. Subsequently, the ADA adopted the Principles of Ethics and Code of Professional Conduct along with an official policy addressing child abuse [1,2]. Our current child welfare services, including services for dental neglect and abuse, has a genesis dating back to the 1960s following the publication of "The Battered Child Syndrome" by Dr. Henry Kempe and colleagues and which focused primarily on physical abuse, and subsequently on sexual abuse [3]. Because the evolutionary development of legal responses to pediatric dental abuse and neglect has never been a primary focus of legislatures [4], the recognition by dental professionals of their role as mandatory reporters has been somewhat slower than recognition by other health care professionals serving the medical needs of children [5]. Today, dental professionals are clearly recognized as mandatory reporters of oral injuries indicating possible child abuse or child neglect [6].

Dental neglect may occur when a parent or child's main adult care provider has been properly alerted by a health care professional regarding the nature and extent of the child's dental condition, the specific treatment needed, and the mechanism of accessing that treatment [7]. Dental neglect may manifest as cavities in baby teeth, "rotting teeth," gum disease, gingivitis, failure to follow through with agreed-on treatment regimens, communication deficiencies or inability to speak, and lack of functionality due to complications from tooth decay, with tooth decay being the single most commonand preventable-chronic childhood disease [8]. According to the Child Abuse Prevention and Treatment Act of 1974, child abuse and neglect is defined as "at a minimum, any recent act or failure to act on the part of a parent or caretaker which results in death, serious physical or emotional harm, sexual abuse or exploitation; or an act or failure to act which presents an imminent risk of serious harm [9]."

Michael Wald of Stanford Law School has noted that "[n]eglect and poverty have always been closely linked," and although neglect has not substantially decreased in twenty years and served as a basis for child protection service interventions, researchers and practitioners have asserted for over 40 years that there is a "deep failure of policymakers to acknowledge the problems in 'neglectful' families, and take the steps necessary to meet the needs of their children-the 'neglect of neglect [10]'”

The issue to address is how to respond and attempt to prevent pediatric dental abuse and neglect? Pediatric dental abuse is often the easier condition for dental professionals to identify, but dental neglect is perhaps more problematic in many instances [11]. If a parent or caregiver obtains a dental treatment plan, but fails to follow through with the child's treatment, how would the dentist be made aware in the event that the parent or caregiver simply does not bring the child back to the same dentist? Currently, there is no mechanism by which dentists might otherwise be made aware that the patient they are treating has previously been diagnosed and provided with a treatment plan that has been ignored or not complied with by the parent or caregiver. Noncompliance with children's dental treatment plans may constitute acts of legal child neglect. Such a case triggers the mandatory reporting requirement imposed on dentists and dental care providers.

One possible solution to this recurring scenario would be to establish either statewide or regional digital encrypted registries of dental protected health information ("PHI"). Encryption [12] processes for data should be consistent with the guidelines adopted by the National Institute of Standards and Technology (NIST) [13]. The registry would allow dental providers to post the patient's treatment plan in a manner whereby other dental professionals might be able to access the information without compromising the medical privacy rights of the patient as [14] defined in the Health Insurance Portability and Accountability Act of 1996 [15] ("HIPPA"). HIPPA provisions do not "inhibit reporting of child abuse and neglect [16]."

A digital data treatment registry based upon the Medicaid billing procedure in which teeth requiring treatment are registered would provide a method for dental care providers to ensure that those patients with pre-existing treatment plans have been 
followed. In the event that the patient has such a treatment plan recorded in the registry filed under the dental license number of the dentist who crafted the treatment plan and the patient's contact information, determining whether a child dental patient has had his or her dental needs neglected would be a matter of cross checking the information contained the regional or state registry [17]. Currently, no such registration system is utilized, and those dentists who provide treatment to children who may have already visited a dental office, had a treatment plan proposed, but where parents or caregivers have failed to attend to the child's dental needs, the registry system would help protect the interests of child patients who may be unable to fend for themselves [18].

Because all dental professionals are by law mandatory reporters of child abuse and neglect, the adoption of digital registry systems would help ensure proper medical and dental care for child patients. The pre-existing legal duty to report to state child welfare authorities those patients thought to be victims of abuse or neglect would be easier for dentists to comply with if digital dental treatment plan registries were adopted statewide or across regional areas where municipalities spread into more than one state's jurisdiction. Creating encrypted digital dental registry systems will not put an end to all forms of pediatric dental abuse and neglect, but it would create a method to quickly identify those patients who have been provided dental treatment plans only to have the patient's parent or care provider fail to follow through and obtain the needed medical or dental services. The most significant beneficiaries of such registries would clearly be those children suffering the consequences of untreated dental abuse or neglect.

\section{References}

1. Professor of Clinical Law \& Director, Juvenile Law Clinic, Tulane Law School, New Orleans, LA.

2. American Dental Association Council on Ethics, Bylaws and Judicial Affairs, American Dental Association Principles of Ethics and Code of Professional Conduct, with Official Advisory Opinions Revised to April 2012. American Dental Association, Chicago, USA.

3. Kempe C, Silverman F, Steele B, Droegemueller W, Silver HK (1962) The Battered-Child Syndrome. JAMA 181(1): 17-24.

4. See Paulson M (1967) Child Abuse Reporting Laws: the Shape of Legislation. Columbia Law Rev 67(1): 1-46.

5. Katner D, Brown C (2012) Mandatory Reporting of Oral Injuries Indicating Possible Child Abuse. JADA 143(10): 1087-1092.

6. Katner D, Brown C, Fournier S (2016) Considerations in Identifying Dental Neglect and the Legal Obligation to Report. JADA 147(10): 812816.
7. California Society of Pediatric Dentists (1989) Dental Neglect: When to Report. California Pediatrician 31-32.

8. Baker L (2012) Decay of Baby Teeth May be Linked to Obesity, Poor Food Choices, Study Suggests [press release]. Buffalo, NY: University at Buffalo, The State University of New York, USA.

9. Child Abuse Prevention and Treatment Act (CAPTA) of 1974 (Pub L No 93-247), as reauthorized by Keeping Children and Families Safe Act of 2003 (Pub L No. 108-36), 42 U.S.C. §5106(g); 2003.

10. Wald M (2015) Beyond CPS: Developing an Effective System for Helping Children in Neglectful Families. Child Abuse \& Neglect 41: 49-66.

11. Katner D, Brown C, Fournier S (2016) Considerations in Identifying Pediatric Dental Neglect and the Legal Obligation to Report. JADA 147(10): 812-816.

12. For the legal definition of encryption see 45 CFR 164.304.

13. NIST is a unit of the US Commerce Department, formerly known as the National Bureau of Standards.

14. The American Medical Association has incorporated instructions on its website (AMA.HIPPA Security Rule: Frequently Asked Questions Regarding Encryption of Personal Health Information)for professionals identifying instances of child abuse or neglect who still seek to comply with the privacy laws entitled "HIPPA." The material advises: Where child abuse victims or adult victims of abuse, neglect or domestic violence are concerned, other provisions of the Rule apply: Child abuse or neglect may be reported to any law enforcement official authorized by law to receive such reports and the agreement of the individual is not required (45 CFR 164.512(b)(1)(ii)).Adult abuse, neglect, or domestic violence may be reported to a law enforcement official authorized by law to receive such reports (45 CFR 164.512(c)):If the individual agrees; If the report is required by law; orIf expressly authorized by law, and based on the exercise of professional judgment, the report is necessary to prevent serious harm to the individual or others, or in certain other emergency situations (see 45 CFR 164.512(c)(1)(iii)(B)).Notice to the individual ofthe report may be required (see 45 CFR 164.512(c)(2)).

15. HIPAA, also known as Public Law 104-191,provides data privacy and security provisions for safeguarding medical information. Sections of the law establish exceptions to nondisclosure of medical information which is otherwise private, including whenever disclosures are "required by law"(164.512(a); whenever there is reasonable belief that that the individual has been subjected to domestic violence, abuse, or neglect $(164.502(\mathrm{~g})(5)$; or for disclosure of information of public health activities which include prevention of injuries as well as disclosure to an appropriate government authority authorized by law to receive reports of child abuse or neglect (164.512(b)(1).

16. Davidson H (2003) The Impact of HIPPA on Child Abuse and Neglect Cases, Child Law 22(1): 11-13.

17. Katner D, Brown C, Fournier S. Considerations in Identifying Pediatric Dental Neglect and the Legal Obligation to Report. JADA 2016:147(10): 812-816.

18. See 45 CFR 164.512(f)(3), et seq., responding to a request for PHI about a victim of a crime, or child abuse or neglect (45 CFR 164.512 (C)(1)(iii) (B)). 


$\begin{array}{ll}\text { BIOMEDICAL } & \text { Assets of Publishing with us } \\ \text { - GeSEARCHES } & \text { Global archiving of articles } \\ & \text { - Immediate, unrestricted online access } \\ & \text { - Rigorous Peer Review Process } \\ & \text { - Anttp://biomedres.us/ }\end{array}$

